\title{
FORMANDO O DOCENTE EM TRABALHO: PROFISSIONAIS LIBERAIS E SUA CONSTRUÇÃO DE SABERES PEDAGÓGICOS
}

\author{
Julia Hélio Lino Clasen ${ }^{1}$ \\ Lee Elvis Siqueira de Oliveira ${ }^{2}$
}

A problemática se dá pela insegurança e a falta de preparo pedagógico dos profissionais liberais que optaram pela carreira docente. Objetivamos compreender como se constitui docente o profissional liberal no ensino técnico. Objetivos específicos: investigar a opção da escolha pela docência do profissional liberal; identificar a percepção do pesquisado com relação a sua formação; reconhecer os fundamentos teóricos práticos de um docente; elencar os desafios encontrados pelos docentes entrevistados. A metodologia, sendo sua natureza uma pesquisa aplicada. Predominantemente qualitativa e bibliográfica com a utilização de autores como Schön (2000); Nóvoa (1992; 1999; 2002); Zabalza (2004); Cunha (2002; 2010), Volpato (2010) e Tardif (2005). Selecionamos oito professores do IFSC - Criciúma. Os resultados obtidos expressa a cultura docente em colocar a responsabilidade do aprendizado somente no estudante, que o professor tem o papel de "transmitir" conhecimentos, se o estudante aprende ou não é algo que devem resolver por si próprios.

Segundo Tardif (2005) e Masetto (2003), a metodologia de ensino é um valioso componente no processo de aprendizagem e auxilia na permanência e no êxito dos estudantes, pois quando se consegue a atenção e o interesse dos estudantes facilita as relações que os mesmos fazem para a aprendizagem. Em reuniões pedagógicas, de área ou conversa informal com os professores, percebeu-se a necessidade de um trabalho específico sobre metodologia de ensino. Partiu-se do questionamento: a falta de conhecimento metodológico dos docentes das áreas técnicas do Instituto Federal de Santa Catarina, IFSC, interfere no processo de aprendizagem dos estudantes? Neste sentido, acredita-se que esta pesquisa contribuirá com o processo de aprendizagem dos estudantes em sua permanência e êxito.

\footnotetext{
${ }^{1}$ Instituto Federal de Santa Catarina - IFSC. julia.clasen@ifsc.edu.br

${ }^{2}$ Instituto Federal de Santa Catarina - IFSC. lee.oliveira@ifsc.edu.br
} 


\section{CONTEXTUALIZANDO A QUESTÃO}

Nos Institutos Federais, a exigência em termos de dispositivos legais para exercer a função docente nas áreas técnicas resume-se em formação técnica; em Criciúma, os professores são arquitetos ou engenheiros. "As práticas, por mais concretas e simples, não existem soltas [...] por isso por trás de qualquer prática existe uma teoria."(MARQUES, 2003, p. 101). Assim, é uma atividade, condição humana, portanto, social. Nossa primeira pesquisa nos revelou que devíamos dar continuidade, pois nos mostrava o que os docentes conheciam sobre as teorias pedagógicas. Se havia dificuldades, queríamos descobrir o que os levou à docência. Marques (2003, p. 92) nos afirma que "é condição para a pesquisa uma dúvida precisa e bem determinada, o centramento em delimitado tema."

Assegura a LDB (1996) em seu art. 13 que os docentes incumbir-seão de "elaborar e cumprir plano de trabalho, segundo a proposta pedagógica do estabelecimento de ensino", ainda, "zelar pela aprendizagem dos alunos". Sendo um dos princípios: "a participação dos profissionais da educação na elaboração do projeto pedagógico da escola", significa dizer que os docentes devem participar efetivamente de todo o processo de planejamento da instituição. No entanto, pela sua formação puramente técnica, por vezes, não conhecem a legislação. Inclusive a que indica ao próprio sistema ofertar a formação dos docentes em trabalho.

O exposto fica confirmado pela LDB (1996), "a formação dos profissionais da educação, de modo a atender às especificidades do exercício de suas atividades." Afirma Tardif (2005) que tanto em suas bases teóricas quanto em suas consequências práticas, os conhecimentos profissionais são evolutivos e progressivos, necessitando, portanto, de uma formação contínua.

Reconhecemos que o contexto educacional escolar traz à tona vários assuntos importantes e contraditórios. Envolvendo docentes, discentes e pesquisadores, busca-se por meio da pesquisa tentar resolver alguns de seus problemas. Neste escopo, nos afirma Marques (2003, p. 92) que o tema construído deve decorrer "de experiências antecedentes, de saberes anteriores, visto como insuficientes e limitantes". 
Assim, como o documento é decorrente das inquisições percebidas, "enunciar uma hipótese é, portanto, ter uma proposta de encaminhamento do tema" (MARQUES 2003, p. 95). Continuou-se a pesquisa com a participação do grupo.

\section{FORMAÇÃO DOCENTE: TRAJETO HISTÓRICO}

Discutir os meandros da educação é um campo complexo, no entanto, este tema ganha uma conotação diferenciada quando trata de profissionais liberais que optaram pela docência como perspectiva de profissionalização ou mesmo por mera oportunidade de trabalho. No dizer de Marques (2003, p. 100) "no entrecruzar-se de muitos assuntos às vezes se pesca o peixe que se procurava."

O conhecimento técnico sobre os conteúdos a serem ministrados necessita de um suporte pedagógico para possíveis desafios da prática. Diante da afirmativa, tentamos solidificar a investigação. "O título deve contemplar o tema, ou problema [...] quanto a forma de ele se enunciar como pretensão de saber posta discussão". (MARQUES, 2003, p. 95).

Assim, recorremos a fragmentos históricos da educação escolar. De acordo com Nóvoa (1992), a Europa tentava desenhar o perfil do professor ideal, e esta foi uma referência importante na história da profissão docente, ocorrendo na segunda metade do século XVIII. A partir de questionamentos, organizou-se um movimento de estatização do ensino, mas foi somente no final do século XVIII que se iniciou a cobrança de uma licença ou autorização do Estado para poder ensinar, exigia-se um exame para aqueles que preenchessem determinadas condições.

A partir da obrigatoriedade desta licença que realmente deu-se o momento decisivo no processo de profissionalização das atividades docentes. Este documento constituiu o suporte legal no exercício da docência. (NÓVOA, 1992). Perceber a formação docente na realidade e tentar compreender suas mazelas, necessariamente, remete a entender o seu percurso. "As escolas normais estão na origem de uma verdadeira mutação sociológica do corpo docente". (NÓVOA, 1992, p. 18). A profissão docente consolida-se no século XVIII e a criação de instituições de formação só acontece em pleno século XIX, sendo as escolas normais para os professores uma grande conquista.

O contexto pedagógico que encontramos na Universidade e nos Institutos Federais aparenta pouca preocupação com a formação pedagógica deste docente, ou há desconhecimento dos saberes destes profissionais. 
Contudo, para haver a preocupação, deve-se primeiro conhecer a importância deste trabalho, para priorizá-lo ou não. “Uma prática profissional é o domínio de uma comunidade de profissionais que compartilham, nos termos de John Dewey, as tradições de uma vocação". (SCHÖN, 2000, p. 36). Vocação esta compreendida na atualidade como uma questão cultural e política.

Mesmo que sejam diferentes entre $\mathrm{si}$, as pessoas dentro de uma profissão partilham com seus pares um conjunto de conhecimentos comuns, organizados. Portanto, tratar o docente no singular compromete qualquer forma de pesquisa. Seria um olhar ingênuo, reducionista, simplesmente criticar a postura destes profissionais em seus postos de trabalho, ou seja, a sala de aula.

Paulo Freire (1991, p. 58) afirma que "Ninguém começa a ser educador numa certa terça-feira às quatro horas da tarde. [...] A gente se faz educador, a gente se forma, como educador, permanentemente, na prática e na reflexão sobre a prática".

Seja com os bons ou maus exemplos, todos foram necessários para a formação desta incompleta identidade de professor. (CUNHA; ZANCHET, 2010). Para o profissional liberal que está em sala de aula, seu aprendizado pedagógico é decorrente da sua vivência como estudante, de suas experiências pessoais e familiares, da observação dos mais diferentes tipos de professores e suas práticas.

Os documentos norteadores de educação, emanados dos órgãos competentes, tratam de uma pedagogia focada no aprender, perceber 0 discente como sujeito do processo. São várias as indicações metodológicas para que os estudantes aprendam o que é necessário, o que lhe é proposto.

Para Nóvoa (1999), a troca de relatos dos experimentos de docentes e sua produção de saberes tornam sólidos os espaços dedicados à formação. Sendo em grupo, o docente desempenha o papel de discente e docente, formando-se ao promover a formação do outro. E, no entanto, este é o único processo que pode conduzir a uma transformação de perspectiva e a uma produção pelos próprios professores a saberes reflexivos relevantes, porque proporciona a revisão de sua prática, observa o discurso dos colegas, há uma análise conjunto das percepções de cada membro do grupo.

Sobre a formação continuada de docentes, Nóvoa (1992), assevera 
que promover uma formação individualizada será útil na medida em que o docente se aproprie de conhecimentos e técnicas das quais sabe que necessita. Isso também gera outro problema: não forma um grupo, e sim, um aglomerado de docentes.

A formação deverá primar pelo conjunto, pelo coletivo. Práticas que tomem como referência as dimensões coletivas contribuem para a emancipação profissional e para a consolidação de uma profissão que é autônoma na produção dos seus saberes. É mister diversificar as metodologias, criar situações onde o docente possa estabelecer uma relação do seu saber com os demais saberes, relacionando com a ciência. O docente vislumbra o seu projeto de investigação. Quem reflete, debruça-se sobre algo e, neste caso, à prática docente, à luz de teorias da própria prática, de suas ignorâncias e saberes. (NÓVOA, 1999).

Para Tardif (2005), os saberes são a convergência de vários saberes provenientes de contextos diferenciados, saberes da sociedade, das instituições de ensino, dos profissionais educacionais... Enfim, saberes construídos na sua esfera social.

Nesse sentido, de acordo com Volpato (2010), quando o profissional liberal se torna professor, não há um tempo nem espaço suficiente para que ele reflita sobre seu novo cargo, pois em toda a sua formação acadêmica, o foco da sua reflexão era a profissão específica e é esta que vai se constituindo, estruturando-se, tomando forma, e não a de docente.

Os professores devem possuir conhecimentos, habilidades e atitudes próprias da docência, que só será uma atividade profissional reconhecida na medida que realizarmos uma formação profissional contínua, específica, acreditada e reconhecida. Somente o conhecimento específico técnico não é o bastante para ensinar. (CUNHA; ZANCHET, 2010).

Todas as organizações buscam se superar, prestar serviços de excelência e a educação escolar não pode ficar à margem da sociedade civil organizada.

PROFISSIONAL LIBERAL: DA PRÁTICA TÉCNICA À TEORIZAÇÃO PEDAGÓGICA 
Marques (2003 p. 112) nos adverte que "[...] cada passo da pesquisa necessita de sua consistência e duração".

Para o levantamento de dados, partindo do primeiro objetivo, foram analisados os currículos dos docentes do IFSC Criciúma. Dos 22 profissionais liberais que se tornaram docentes, apenas três possuem curso de formação pedagógica, confirmando a pouca capacitação oferecida a esses profissionais que se tornaram professores.

Dessa forma, em seus resultados preliminares por meio da tabulação e análise de dados, foram pesquisados 13 docentes com os questionamentos sobre a metodologia utilizada e sua interferência na aprendizagem dos estudantes, na ânsia de atingir o objetivo. As respostas foram unânimes, $100 \%$ dos entrevistados responderam que a metodologia interfere na aprendizagem dos estudantes e indicam como justificativa as diferenças individuais, respeito às peculiaridades dos estudantes, "facilitando" as supostas dificuldades desses. De acordo com as respostas, todos os entrevistados utilizam procedimentos diferenciados. As aulas expositivas dialogadas são as mais citadas, seguidas de seminário, oficinas e laboratório. Praticamente todos consideram importante a formação sobre Metodologia de ensino, com exceção de um profissional.

Para atingir os novos objetivos propostos, na segunda etapa da pesquisa, para que verificássemos o que os levou à docência, como metodologia, além de entrevistas, utilizamos os documentos dos docentes para levantamento de alguns dados. Selecionamos oito professores do IFSC Criciúma, com diferentes formações: três doutores, um mestre, um mestrando e três graduados. Todos são engenheiros e uma, arquiteta. Dos oito, dois deles com curso de aperfeiçoamento em formação docente. Para preservar o anonimato das respostas, iremos identificar os professores por letras de $\mathrm{A}$ até $\mathrm{H}$, de forma aleatória.

Questionados sobre o que os motivou se tornarem docentes, várias respostas surgiram destes profissionais, porém o trabalho prévio com "treinamento" de pessoal é a resposta mais frequente. Há quem respondeu que só começou na docência pela questão de oportunidade de trabalho e outra resposta foi a identificação com os conteúdos exigidos em edital para o 
concurso de ingresso na instituição, mostrando que alguns profissionais liberais realmente "caem de paraquedas" na docência: Segundo o professor E: "a vaga (para docente) era exatamente aquilo que eu fazia no meu atual emprego, segundo emprego que tenho. [...] uma vaga que exigia um profissional muito parecido com aquilo que fazia, então eu decidi." E ao ser questionado sobre sua preparação respondeu:

\begin{abstract}
Não me sentia nem um pouquinho [preparado], foi inclusive a primeira aula que eu tive aqui no IFSC, foi a primeira aula oficial da minha vida eu saí, assim, aterrorizado da sala, acho que foi uma péssima aula. Foi muita pressão. Na hora eu pensei, meu Deus o que faço aqui? Quero sair correndo, queria me esconder. Então com certeza não me sentia preparado. E certamente eu não estava mesmo. (PROFESSOR E).
\end{abstract}

Dos oito docentes pesquisados, cinco não se sentiam preparados para a docência quando começaram sua carreira. Uma professora afirmou que se sentia preparada, justamente uma que possuía o curso de formação pedagógica, antes de iniciar as atividades docentes. Percebemos a importância da formação pedagógica no preparo do professor, servindo de base e, principalmente, oferecendo confiança, assim evitando um "trauma" em sala de aula. Em outra resposta, um professor diz que em sua primeira aula no Instituto estava totalmente despreparado, ficou em pânico e até se questionou o que estava fazendo ali. O próprio professor confessa que aquela aula foi horrível, não só como experiência para si, também para os estudantes.

Zabalza (2004) aborda as competências que o docente deve ter: conhecimentos específicos da disciplina, o que nenhum entrevistado apontou como dificuldade; habilidades específicas de comunicação, de recursos didáticos, de avaliação, nas respostas aparecem sutilmente como dificuldade; e de atitudes próprias dos formadores como disponibilidade, empatia e ética profissional.

Para Tardif (2005), uma epistemologia da prática profissional é fundamental para os professores compreenderem os saberes e sua a natureza.

De acordo com os dados, a experiência em sala de aula é a responsável pela formação docente destes profissionais. Além desta, a repetição de bons exemplos de outros professores e as conversas com colegas são os itens mais apontados como fundamentação para o exercício da 
docência. Alguns docentes ainda compreendem o fazer educativo como um ato de transmissão ou de extensão de um saber.

Mesmo não sendo as únicas referências para a docência, os exemplos de professores na sua vida escolar são produtivos e não podem ser desprezados, pois constituem representação sobre o que é ensinar e aprender, e que esses exemplos vão orientar o processo de docência. (CUNHA; ZANCHET, 2010).

Da entrevista, ainda, indicamos um professor o qual afirma não se basear em nenhuma teoria pedagógica, pois entende que não são aplicáveis em sala de aula, porque as turmas são diferentes umas das outras e, além disso, as teorias estão muito distantes da realidade:

Às vezes colocam algum pensador que diz como dar aula e não adianta, cada turma é uma turma diferente, então tem que ser tua experiência em sala de aula, esse semestre, este ano é uma turma, semestre que vem, vem outra turma e tu tens que se adequar. (PROFESSOR D).

Esta resposta indica a percepção que o docente tem do que seja uma teoria de aprendizagem. É passivo de pensar que, assim como não compreende, terá dificuldade em relacionar a teoria com a prática em aula, bem como estabelecer uma metodologia condizente.

Quando questionados sobre suas dificuldades na docência, o que chama a atenção nas respostas é que há uma tendência em colocar o estudante como obstáculo no aprendizado: que são desinteressados, cansados, mal educados e imaturos para o estudo. Um dos entrevistados salientou que este desinteresse dos estudantes é maior no ensino de matérias técnicas, pois alguns estão na Instituição não por identificar-se com a formação técnica, e sim pelo status de escola com ensino de qualidade e gratuito. Contudo, em algumas respostas o professor traz para si a responsabilidade de motivar os estudantes, conhecendo melhor seu universo e seus interesses.

Segundo Cunha e Zanchet (2010), costuma-se esperar dos docentes universitários, e no nosso caso comparamos com o ensino técnico de nível médio, um conhecimento específico de sua área, baseado nos rigores da ciência e em um exercício profissional que legitime esse saber na prática.

Desta maneira, temos um professor que exige um nível de 
conhecimento moldado pela sua formação universitária, em alguns casos e pela sua formação como pesquisador em pós-graduação stricto sensu. Por fim, perguntamos sobre as necessidades dos professores para o exercício da docência. Três categorias se destacam pela incidência: formação docente, capacitação em novas tecnologias e metodologias e capacitação para entender o perfil do jovem estudante.

\begin{abstract}
Uma é atualização em mídias, este problema principalmente com o integrado, porque os tempos são outros, hoje eu fico imaginando pegar quatro ou cinco aulas de matemática, hoje em dia, em cinco aulas eles fazem um monte de coisas junto, ao mesmo tempo [...], multitarefa, e a gente quer que o aluno seja monotarefa naquele momento, que toda a atenção do mundo seja voltada para tua disciplina. (PROFESOR G).
\end{abstract}

Identificamos também por meio das entrevistas que os cursos de formação e capacitação docente devem oferecer especial atenção à docência voltada para a geração de estudantes de hoje, de como as metodologias podem ser úteis para gerar o interesse dos mesmos. Um dos entrevistados acredita que o sistema de ensino atual é fracassado e que uma reforma profunda na educação se faz necessária.

O que surpreende é este desejo de entender melhor o jovem desta geração:

\begin{abstract}
Neste momento, é uma dificuldade esse público mais jovem, para mim consigo me dar melhor com público mais velho, o pessoal do subsequente da escola é tranquilo, agora com o público mais jovem é um problema. [...] saber como o adolescente age, como é que ele faz, para que a gente possa atingir, chegar no mundo dele [...]. Uma outra palestra que vi, a professora disse o seguinte: enquanto a gente está falando o aluno começa a viajar [...] a hora que ele volta da viagem a aula está quase acabando, então acho que saber lidar com isto. (PROFESSOR C).
\end{abstract}

Nóvoa (1999) defende que a formação de professores não é apenas o aperfeiçoamento, a qualificação ou a progressão na carreira docente.

Todos os discursos sobre educação escolar em todos os níveis, bem como os dispositivos legais apontam para um trabalho de excelência. Contudo, não acontecerá por meio de decreto. A qualidade almejada virá com auxílio de uma formação contínua focada no sujeito, partindo de suas percepções sobre o seu ato de ensinar. Faz-se necessário uma percepção da cultura em que 
estamos imersos, para poder, respeitando a história, propor novas práticas.

\section{CONCLUSÃO}

Esses são os primeiros resultados de uma pesquisa que aponta uma caminhada árdua, desafiadora e gratificante, pois propiciou uma reflexão sobre a prática docente a partir da análise de conteúdo das falas de seus atores.

O estudo demonstrou que a atualização e compreensão de diferentes metodologias é fundamental, no entanto, o docente necessita compreender-se como sujeito do e no processo, assim como o estudante, porém com papéis diferenciados e não somente trabalhar com regras e roteiros prontos para aperfeiçoar o perfil do estudante.

Na percepção do pesquisado, sua formação é efêmera, se sentem inseguros, necessitando de orientações pedagógicas permanentes. Revelaramse, ainda, os fundamentos teóricos práticos de um docente em curso técnico para alguns dispensáveis, outros como um conjunto de teorias, ainda decorrentes das experiências vivenciadas, ou por estar seguindo exemplo de determinados professores.

Ao elencar as dificuldades encontradas, essas recaem sobre o perfil dos estudantes, bem como da estrutura da escola, na atualidade. O docente se percebe fora do cotidiano pedagógico, exclui-se da problemática. Reconhece ser imperativa a formação docente, a capacitação em novas tecnologias e metodologias e formação para entender o perfil do jovem estudante.

Para o grupo de docentes pesquisados, é possível aferir que a visão interacionista, o enfoque dialético, talvez esteja somente em seu discurso. Suas respostas evidenciam a necessidade de mudanças externas a ele. Todas as necessidades elencadas pelos profissionais são reais, em um contexto. Contudo, há que se fazer uma reflexão para propor uma formação a partir de sua percepção docente, mas não apenas dela.

É unânime o discurso entre os docentes de que a formação focada nos saberes pedagógicos é uma necessidade. Existe a cultura de colocar a responsabilidade do aprendizado somente no estudante, no caso o professor tem o papel de "transmitir" conhecimentos, se o estudante aprende ou não é algo que eles devem resolver por si próprios. 
Essas respostas nos levam a perceber que mais indagações surgem ao concluir esta etapa, pois uma pesquisa é mais um passo da caminhada do conhecimento.

\section{REFERÊNCIAS}

BRASIL. Lei de Diretrizes e Bases da Educação Nacional, n. 9394. Brasília: 20 de dezembro de 1996. DOU.

CUNHA, Maria Isabel da; ZANCHET, Beatriz Maria Boéssio Atrib. A problemática dos professores iniciantes: tendência investigativa no espaço universitário. Revista Educação. Porto Alegre, v. 33, n. 3, p. 189-197. Set/Dez. 2010.

<http://revistaseletronicas.pucrs.br/ojs/index.php/faced/article/viewFile/6999/57 $>17$. Acesso em: 18 Set. 2014.

FREIRE, Paulo. A educação na cidade. São Paulo: Cortez, 1991.

MARQUES, Mário Osório. Escrever é preciso: o princípio da pesquisa. 4. ed. Rio Grande do Sul: Unijui. 2003.

MASETTO, Marcos Tarciso. Competência pedagógica do professor universitário. São Paulo: Summus, 2003.

NÓVOA, António. Formação de professores e profissão docente. Lisboa: Dom Quixote, $1992 . \quad$ Disponível em: http://core.kmi.open.ac.uk/download/pdf/12424596.pdf Acesso em: 16 de Nov. de 2014.

NÓVOA, António. O passado e o presente dos professores. In: Profissão Professor. 2 ed. Porto: Porto Editora, 1999. Disponível em: http://www.dle.ufms.br/carol/Profissao_Professor.pdf. Acesso em: 18 de Set. de 2014.

SCHÖN, Donald A. Educando o profissional reflexivo: um design para o ensino e aprendizagem. Porto Alegre: Artmed, 2000.

TARDIF. Maurice. Saberes docentes e formação profissional. Petrópolis: Vozes, 2005.

VOLPATO, Gildo. Profissionais liberais professores: Aspecto da docência que se tornam referências na educação superior. Curitiba: Editora CRV, 2010.

ZABALZA, Miguel A. 0 ensino universitário: seu cenário e seus protagonistas. Porto Alegre: Artmed, 2004. Disponível em: $<$ http://www2.pucpr.br/reol/pb/index.php/dialogo?dd1=809\&dd99=view\&dd98=p b. >Acesso em: 18 Set. 2014. 